KANSAS JOURNAL of MEDICINE

\section{Understanding Medication Adherence in Patients with Limited English Proficiency}

Luke Kahler, MS-4, Joseph LeMaster, M.D., MPH University of Kansas School of Medicine, Kansas City, KS Department of Family Medicine and Community Health Received July 26, 2021; Accepted for publication Oct. 12, 2021; Published online Jan. 11, 2022 https: doi.org 10.17161 kjm.voll5.15912

\section{ABSTRACT}

Introduction. Approximately $41.6 \%$ of the U.S. population who speak a language other than English (20\% of the total population) have limited English proficiency (LEP) status. Health outcomes for patients with LEP status or who are language discordant (speak a different language than their clinicians) have been studied in several settings, including hospital and outpatient, with results widely demonstrating that these patients have worse outcomes when a professional interpreter is not used consistently. The aim of this study was to investigate the impact of preferred language and language discordance on medication adherence.

Methods. Data were collected through the review of pharmacyacquired medication profiles for three primary language cohorts: English, Nepali, and Spanish. Total Days of Adherence, Adherence Ratio, and Maximum Days Non-Adherent were calculated and compared between language groups. The statistics were examined for regular and long-acting insulin, metformin, and ACE inhibitors, testing for differences between language groups, and those who experienced greater and less than the median value for language concordant clinical encounters.

Results. The most adherent group overall (highest Adherence Ratio) were the Nepali-speaking patients, but the results showed high variability across outcomes and medications.

Conclusions. After adjustment and stratification for greater and lesser language concordant patient visit experience, it was found that language-spoken plays an important role in the clinical encounter, and that LEP patients could have improved outcomes in their adherence to medications by having providers who speak their language or use an interpreter. Kans J Med 2022;15:31-36

\section{INTRODUCTION}

The 2009-2013 American Community Survey reported that 41.6\% of the U.S. population who speak a language other than English (20\% of the total population) have limited English proficiency (LEP) status. ${ }^{1}$ Health outcomes for patients with LEP have been studied in a number of settings, including hospital and outpatient, with results widely demonstrating that LEP patients have worse outcomes when a professional interpreter was not used consistently. ${ }^{2,3}$ Refugees and new immigrants often have LEP status during their early resettlement period in the U.S.; data have shown that $62 \%$ of refugees are limited in their English proficiency. ${ }^{4}$
When compared to non-refugees, refugees have a higher prevalence of chronic disease. ${ }^{5}$ Even when compared to their U.S.-born ethnic counterparts, refugees have higher rates of diabetes. ${ }^{6,7}$ Health education promoting physical activity and optimal self-care for LEP patients with Type 2 diabetes mellitus (T2DM) in primary care settings is often ineffective, leading to poorer control of blood glucose and poorer health outcomes than among English-speaking patients. ${ }^{8}$ Other significant barriers to effective management of chronic disease, including diabetes mellitus, in refugees with LEP include: varying cultural beliefs about illness, ${ }^{2}$ ineffective communication between provider and patient, ${ }^{9}$ decreased access to pharmacy and medication services, ${ }^{10}$ and decreased health literacy. ${ }^{11}$ However, a significant paucity of published research explored barriers to medication and pharmacy services among resettled refugees. ${ }^{10}$

Thus, the aim of this study was to quantify the impact of LEP status on diabetes-related medication adherence over the course of 12 months. The authors hypothesized that speaking English would correlate with higher Adherence Ratios and that LEP status would correlate with lower Adherence Ratios (other studies have demonstrated improvement in clinical outcomes with use of interpreters).

Patients with LEP who speak Nepali or Spanish were compared with English-speaking patients as a control group. The primary outcome of interest was number of days of nonadherence with their medication regimen as determined by days adherent to medication divided by days prescribed medication.

\section{METHODS}

This study was approved as a quality improvement study by the University of Kansas Medical Center Institutional Review Board.

Study Design. Data collection for this observational study was accomplished through chart review of patient medical records at the Family Medicine clinic of the University of Kansas Health System. Access to protected health information (PHI) was limited to researchers who were members of the treatment team directly providing care to study participants. Pharmacy data were collected over a six month period from June 1, 2018 to May 31, 2019.

Participants. All participants were established patients of the University of Kansas Health System. Participants in the study were selected via electronic medical record (EMR) chart review to meet the following qualifications: preferred language as Nepali, Spanish, or English; at least 18 years old; diagnosis of T2DM prior to study enrollment; and a hemoglobin Alc ( $\mathrm{HbAlc}$ ) of at least $8 \%$ (representing uncontrolled diabetes mellitus). English speaking patients were included as a control if they identified as Latin(x) for their ethnic status. The Nepali-speaking patients were ethnically Bhutanese former refugees. Most patients in the Nepali cohort were served by a single Nepali-speaking bilingual physician. This was not the case for the Spanish and English-speaking cohort. The English-speaking cohort was composed largely of bilingual, Spanish-speaking patients whose preferred language was English.

Measures. Patients did not contribute patient-reported information in this study. Medication adherence data were collected through a retrospective chart review and through contacting patients' pharmacies. Each patient's medication profile was obtained by contacting the patient's pharmacies, where the investigators determined actual medications 
filled at each pharmacy and which medicines a patient had access to fill. Data collected from the EMR included: patient's medication record (to allow for consideration of longitudinal data), self-reported preferred language, number of language concordant visits, most recent $\mathrm{HbAlc}$, medication refill dates of all diabetes-related medications, total number of medications of any type, and patient demographics (e.g., age, sex, ethnicity, living situation, insurance status, marital status, and presence of currently active EMR patient portal). Language concordance with providers was assessed by review of patient's preferred language status and the bilingual status of the provider in question. All those preferring English as their language also identified "Spanish/Hispanic" as their ethnic group. All language discordant encounters were conducted with the use of a professional medical interpreter, either live or by phone.

Outcomes of Interest. The outcome of interest was Actual Days of Medication Adherence, Adherence Ratio, and Maximum Days NonAdherent. The Adherence Ratio was calculated based on the cumulative number of days of medication supply afforded a patient as a ratio with number of days the patient had been prescribed the medicine, such that:

$$
\text { Adherence Ratio }=\frac{\text { actual number of days adherent to regimen }}{\text { expected number of days adherent to regimen }}
$$

The Actual Days of Medication Adherence was the number of days possible for the patient to use the medication properly based on the quantity dispensed by the pharmacy for each refill over the time of the study. The expected adherence was the total number of days the patient had been prescribed that medicine, starting from their first refill at the pharmacy. This ratio was used as a surrogate for medication adherence because there was a paucity of validated metrics in the literature for measuring patient medication adherence using objective data without collecting information on patient reported medication use directly. ${ }^{12,13}$ The Adherence Ratio was calculated for each medication reported. Maximum Number of Days Non-Adherent was calculated for each medication based on gaps in medication refill data collected from pharmacy medication profiles, such that:

$$
\begin{aligned}
& \text { Maximum Days Nonadherence }= \\
& \text { \# of total days prescribed medication - \# of days supply of medication }
\end{aligned}
$$

In other words, Maximum Days Nonadherence revealed the number of days that the patient did not have access to the medication because it was not picked up from the pharmacy. The three language groups were compared to each other in terms of these outcomes, as well as their most recent HbAlc value and the number of visits with a languageconcordant provider.

Analysis. Stata Inter-cooled Version 10 (Statacorps, Austin, TX) was used for analyses. Demographic variables were centered (subtracted the mean value of each variable from each value) to produce variables that would allow an estimate of baseline values for outcome variables in regression models that had real-world meaning once adjusted. Medication use was measured over 180 days from the time of enrollment. The number of days of medication use was doubled to produce an annualized estimate. This procedure was used for the actual days of medication use and maximum number of days patients were non-adherent.

A one-way analysis of variance was calculated to compare each
KANSAS JOURNAL of MEDICINE MEDICATIONADHERENCE IN LEP PATIENTS

continued.

outcome variable by language group (English, Spanish, or Nepali). A two-tailed significance using F-statistics was calculated, accepting an alpha p value of 0.05 as significant. Bartlett's test of equal variance tested for heteroskedasticity in the dependent variable distribution of each outcome for each different language group. If Bartlett's test was significant, median and interquartile ranges were calculated and a nonparametric median test determined significance.

Next, an ordinary least squares regression was conducted, using a dependent variable for each of the different medication parameters for actual days of medication use and maximum days of non-adherence, separately. Models included data for all participants taking each type of medication. Models were examined for the effect of potential confounding by centered age, sex, marital status, current health insurance (insured or not), total number of medications, most recent $\mathrm{HbAlc}$, and presence of a currently active electronic medical record patient portal. The independent variable of primary interest was selfreported preferred language. Only age and sex were retained in final models, as including other potential confounders had little impact on final adjusted results. All models were weighed by the amount of time data were collected (which varied between patients). For these models, the Breusch-Pagan test (also known as the Cook-Weisberg test) was used for heteroskedasticity. The Breusch-Pagan test approximates the Bartlett's test for heteroskedasticity for one way analysis of variance.

Outcomes for Spanish- and Nepali-only speakers were compared to those who reported bilingual status in English and either Spanish or Nepali. Outcomes were estimated using the linear combination of the constant model term and the beta-coefficient for each language using the Stata post-estimation lincom command, which estimated the 95\% confidence intervals. Non-equivalence of outcomes compared Spanishonly to Nepali-only speakers, using a post-estimation Wald test.

Finally, all models were examined for evidence that language discordant visits impacted the models. The proportion of visits were calculated for each participant that was provided by a language concordant provider (concordance ratio). Participants who preferred English always had a language concordant provider. This was not true for those preferring Spanish or English. Models were examined for evidence of interaction between language and the concordance ratio. Interaction in terms of significance of the Wald test for the multiplicand of the values of those two variables were reported. Mean and standard deviation were reported for each language with a concordance ratio greater than the median value (67\%) against those with lesser values.

\section{RESULTS}

Table 1 shows the demographics of the study participants. In general, Spanish-speaking patients were more often bilingual in English when compared to the Nepali-speaking patients. In fact, the English demographic was comprised of Latin(x) patients who listed English as their preferred language on EMR review and did not require an interpreter for clinical encounters. 
KANSAS JOURNAL of MEDICINE MEDICATION ADHERENCE IN LEP PATIENTS continued.

Table 1. Demographics $(\mathrm{n}=\mathbf{5 9})$.

\begin{tabular}{|l|c|}
\hline Mean age (SD) & $56.4(13.1)$ \\
\hline Sex & $n(\%)$ \\
\hline Female & $36(61.0 \%)$ \\
\hline Male & $23(39.0 \%)$ \\
\hline Preferred language & $n(\%)$ \\
\hline English & $15(25.4 \%)$ \\
\hline Spanish & $21(35.6 \%)$ \\
\hline Nepali & $23(39.0 \%)$ \\
\hline
\end{tabular}

On average, the Nepali-speaking group had a higher recent $\mathrm{HbAlc}$ [10.6 (2.0 SD)] than the Spanish-speaking group [9.8 (1.6 SD)] while taking a greater number of medications overall. The mean number of total medications taken was 18.7 (4.4 SD) for Nepalis and 16.4 (6.8 SD) for Spanish-speaking patients. The English and the Nepali groups were similar regarding total number of medications taken and average HbAlc.

Table 2 reports medication adherence for insulin, metformin, and ACE inhibitors. Some drugs prescribed (i.e., thiazolidinediones, DPP-4 inhibitors, and others) had insufficient data to perform statistical analysis and are not reported. The unadjusted values have been reported for comparison. After adjustment for potential confounders, adherence, as reflected by the total number of days adherent and Adherence Ratio, were higher for both Spanish- and Nepali-speakers compared to English-preference patients for regular insulin and metformin, as well as for the use of ACE inhibitors. This was also true for Neutral Protamine Hagedorn (NPH) insulin for Nepali- but not Spanish-speakers. Nepalis were significantly more adherent than Spanish-speaking patients for ACE inhibitors and regular insulin (but not NPH), in terms of the total number of days adherent; however, the Adherence Ratio only differed between Nepali- and Spanish-speaking patients for ACE inhibitors (Nepali-speakers' ratio was higher). Correspondingly, Maximum Days of Non-Adherence was significantly less for Nepali- and Spanishspeakers compared to English-preference speakers for NPH insulin. This was true for metformin and ACE-inhibitors for Nepalis compared to English preference speakers, but not for Spanish-speakers.

The Maximum Consecutive Days of Non-Adherence demonstrated opposing trends with higher values in the English- and Spanish-speaking groups compared to Nepali-speaking. English- and Spanish-speaking groups had, on average, a longer Maximum Number of Days Non-adherent than their Nepali-speaking counterparts.

After controlling for language concordance between patient and provider, language groups remained significantly different only for regular insulin actual days of use. For medication ratio and maximum days of medication adherence for regular insulin, and for all other medication and all other outcomes, there were no significant differences between language groups once language concordance was controlled. Tests of interaction between preferred language and language concordance were non-significant for all medications and all outcomes.
Because of the systematic variation introduced by the design (i.e., English-speaking patient encounters were language concordant by design), mean and standard deviation values for each medication and outcome by language and concordance group were calculated, using one-way analysis of variance (Table 3). Significant differences between language groups were found only when comparing language concordant Nepali- to English-preference patients. For some comparisons, Bartlett's test for heterogeneity was significant (metformin Adherence Ratio and Maximum Days Non-adherence for language concordant encounters, and ACE Inhibitor actual days and ratio for language non-concordant encounters, and maximum non-adherent days for concordant encounters). For those comparisons, to determine if there was a significant difference between languages in each instance, the outcome variable was transformed by subtracting a constant $k$ (different for each outcome) from the natural log of the outcome (i.e., for Metformin ratio, this $=\ln ($ metformin ratio +1.014$)$ ). This transformed variable had skewness equal to about 0 . The analysis using the transformed variable was repeated. This result effectively corrected the heterogeneity for each of the above comparisons for which it was problematic. None of the transformed comparisons were significant between language groups.

\section{DISCUSSION}

The aim of this study was to investigate medication adherence among LEP patients. To that end, medication profiles collected from pharmacies and the Adherence Ratio for diabetes-related medications differed amongst the studied language groups. Surprisingly, the patients who were least compliant with their medication regimen were the Latin(x) English-preference patients. Despite this finding, the most recent HbAlc measurement in the Nepali and English groups were comparable to each other. This result suggested factors not assessed in this study contributed to adequate control of diabetes other than medication adherence as we measured it and as has been demonstrated elsewhere. ${ }^{12}$ In support of this assertion, the Maximum Days of Non-Adherence was more often longer in the Spanish-speaking and English-preference cohort than in the Nepali-speaking. Since almost all of the English-speaking cohort were assumed also to speak Spanish, the differences noted between the English-speaking cohort and the Nepalispeaking cohort included both cultural and linguistic factors, whereas between Spanish- and English-speaking cohorts, the main differences were more likely to have been linguistic. Most of the Spanish- and English-speaking patients studied were of Mexican descent, thus having a similar cultural background. These findings were at odds with our hypothesis that speaking English would correlate with higher Adherence Ratios and that LEP would correlate with lower Adherence Ratios.9

It is possible that the language spoken by the patient was only one among many factors influencing medication adherence. One study has found that LEP patients with language-discordant physicians were more likely than LEP patients with language-concordant physicians to have poor glycemic control. ${ }^{7}$ Thus, outcomes were improved for LEP patients when the patient and provider can communicate more easily. Our data supported this finding given that the observed differences among language groups dissipated after stratifying patients by language concordance with their providers. The only exception was for 
actual days of using regular insulin, and only for those with above the median level of language concordant visit. Thus, language concordance accounted for most of the above findings.
KANSAS JOURNAL of MEDICINE

MEDICATIONADHERENCE IN LEP PATIENTS

continued.

Table 2. Adjusted ${ }^{\dagger}$ and unadjusted values of medication.

\begin{tabular}{|c|c|c|c|c|c|c|}
\hline \multirow[b]{2}{*}{$\begin{array}{l}\text { Regular insulin } \\
(\mathbf{n}=17)\end{array}$} & \multicolumn{2}{|c|}{ Actual Days Medication Adherence } & \multicolumn{2}{|c|}{$\begin{array}{c}\text { Adherence Ratio } \\
\text { (actual days/expected days of adherence) }\end{array}$} & \multicolumn{2}{|c|}{ Maximum Days Non-Adherent } \\
\hline & $\begin{array}{l}\text { Adjusted mean } \\
\quad(95 \% \mathrm{CI})\end{array}$ & $\begin{array}{l}\text { Unadjusted mean } \\
\text { (SD) }\end{array}$ & $\begin{array}{l}\text { Adjusted mean } \\
\quad(95 \% \text { CI })\end{array}$ & $\begin{array}{l}\text { Unadjusted mean } \\
\text { (SD) }\end{array}$ & $\begin{array}{l}\text { Adjusted mean } \\
\quad(95 \% \text { CI })\end{array}$ & $\begin{array}{l}\text { Unadjusted mean } \\
\text { (SD) }\end{array}$ \\
\hline English & $\begin{array}{c}106 \\
(19-192)^{* * *}\end{array}$ & $\begin{array}{c}44.3 \\
(44.4)\end{array}$ & $\begin{array}{c}0.648 \\
(0.258-1.04)\end{array}$ & $0.444(0.381)$ & $\begin{array}{c}78.6 \\
(-23.7-181)\end{array}$ & $\begin{array}{c}127 \\
(164)\end{array}$ \\
\hline Spanish & $\begin{array}{c}183 \\
(123-242)^{* *}\end{array}$ & $\begin{array}{l}163 \\
(117)\end{array}$ & $\begin{array}{c}0.718 \\
(0.450-0.986)^{* *}\end{array}$ & $0.669(0.376)$ & $\begin{array}{c}35.1 \\
(-35.3-106)\end{array}$ & $\begin{array}{c}41.0 \\
(50.0)\end{array}$ \\
\hline Nepali & $\begin{array}{c}273 \\
(188-358)^{* *++} \\
\end{array}$ & $\begin{array}{c}241 \\
(86.7) \\
\end{array}$ & $\begin{array}{c}0.796 \\
(0.412-1.180)^{* * *} \\
\end{array}$ & $0.714(0.256)$ & $\begin{array}{c}60.0 \\
(-40.8-161) \\
\end{array}$ & $\begin{array}{r}68.7 \\
(62.1) \\
\end{array}$ \\
\hline $\begin{array}{l}\mathrm{NPH} / \\
\text { glargine insulin } \\
(\mathrm{n}=25)\end{array}$ & $\begin{array}{l}\text { Adjusted mean } \\
\quad(95 \% \mathrm{CI})\end{array}$ & $\begin{array}{l}\text { Unadjusted mean } \\
\text { (SD) }\end{array}$ & $\begin{array}{l}\text { Adjusted mean } \\
\quad(95 \% \mathrm{CI})\end{array}$ & $\begin{array}{l}\text { Unadjusted mean } \\
\text { (SD) }\end{array}$ & $\begin{array}{c}\text { Adjusted mean } \\
(95 \% \text { CI })\end{array}$ & $\begin{array}{l}\text { Unadjusted mean } \\
\text { (SD) }\end{array}$ \\
\hline English & $\begin{array}{c}146 \\
(18.9-272)^{*}\end{array}$ & $\begin{array}{c}171 \\
(169)\end{array}$ & $\begin{array}{c}0.611 \\
(0.259-0.963)^{* * *}\end{array}$ & $0.676(0.452)$ & $\begin{array}{c}125 \\
(39.9-209)^{*}\end{array}$ & $\begin{array}{l}102 \\
(176)\end{array}$ \\
\hline Spanish & $\begin{array}{c}122 \\
(32.5-211)^{*}\end{array}$ & $\begin{array}{l}139 \\
(109)\end{array}$ & $\begin{array}{c}0.531 \\
(0.283-0.779)^{* *}\end{array}$ & $0.587(0.302)$ & $\begin{array}{c}90.1 \\
(30.5-150)^{* * *}\end{array}$ & $\begin{array}{c}58.7 \\
(44.0)\end{array}$ \\
\hline Nepali & $212(114-311)^{* *}$ & $\begin{array}{l}209 \\
(128) \\
\end{array}$ & $\begin{array}{c}0.673 \\
(0.398-0.947)^{* *}\end{array}$ & $0.705(0.362)$ & $\begin{array}{c}80.7 \\
(14.7-147)^{*} \\
\end{array}$ & $\begin{array}{l}79.6 \\
(111) \\
\end{array}$ \\
\hline $\begin{array}{l}\text { Metformin } \\
(\mathrm{n}=32)\end{array}$ & $\begin{array}{c}\text { Adjusted mean } \\
(95 \% \text { CI })\end{array}$ & $\begin{array}{l}\text { Unadjusted mean } \\
\text { (SD) }\end{array}$ & $\begin{array}{l}\text { Adjusted mean } \\
(95 \% \text { CI })\end{array}$ & $\begin{array}{l}\text { Unadjusted mean } \\
\text { (SD) }\end{array}$ & $\begin{array}{c}\text { Adjusted mean } \\
\text { (95\% CI) }\end{array}$ & $\begin{array}{c}\text { Unadjusted mean } \\
\text { (SD) }\end{array}$ \\
\hline English & $\begin{array}{c}139 \\
(15.7-263)^{*}\end{array}$ & $\begin{array}{l}134 \\
(121)\end{array}$ & $\begin{array}{c}0.601 \\
(0.239-0.963)^{* * *}\end{array}$ & $0.672(0.456)$ & $\begin{array}{c}107 \\
(24.0-190)^{*}\end{array}$ & $85.3(120)$ \\
\hline Spanish & $\begin{array}{c}173 \\
(100-246)^{* * *}\end{array}$ & $\begin{array}{c}170 \\
(81.8)\end{array}$ & $\begin{array}{c}0.803 \\
(0.590-1.015)^{* * *}\end{array}$ & $0.835(0.206)$ & $\begin{array}{c}42.7 \\
(-5.98-91.3)\end{array}$ & $40.9(47.3)$ \\
\hline Nepali & $\begin{array}{c}200 \\
(145-254)^{* *}\end{array}$ & $\begin{array}{l}205 \\
(115) \\
\end{array}$ & $\begin{array}{c}0.741 \\
(0.582-0.900)^{* *} \\
\end{array}$ & $0.761(0.328)$ & $\begin{array}{c}49.6 \\
(13.1-86.1)^{*} \\
\end{array}$ & $49.8(83.4)$ \\
\hline $\begin{array}{l}\text { ACE inhibitors } \\
(n=21)\end{array}$ & $\begin{array}{c}\text { Adjusted mean } \\
(95 \% \text { CI })\end{array}$ & $\begin{array}{l}\text { Unadjusted mean } \\
\text { (SD) }\end{array}$ & $\begin{array}{c}\text { Adjusted mean } \\
(95 \% \text { CI })\end{array}$ & $\begin{array}{l}\text { Unadjusted mean } \\
\text { (SD) }\end{array}$ & $\begin{array}{c}\text { Adjusted mean } \\
(95 \% \text { CI })\end{array}$ & $\begin{array}{c}\text { Unadjusted mean } \\
\text { (SD) }\end{array}$ \\
\hline English & $\begin{array}{c}116 \\
(17.9-215)^{*}\end{array}$ & $\begin{array}{c}97.7 \\
(102) \\
\end{array}$ & $\begin{array}{c}0.511 \\
(0.166-0.856)^{* *}\end{array}$ & $0.427(0.493)$ & $\begin{array}{c}153 \\
(58.8-248)^{* *}\end{array}$ & $\begin{array}{l}188 \\
(178) \\
\end{array}$ \\
\hline Spanish & $\begin{array}{c}186 \\
(118-255)^{*} \\
\end{array}$ & $\begin{array}{l}184 \\
(111) \\
\end{array}$ & $\begin{array}{c}0.701 \\
(0.460-0.942)^{* * *} \\
\end{array}$ & $0.692(0.331)$ & $\begin{array}{c}65.1 \\
(-1.05-131) \\
\end{array}$ & $\begin{array}{r}64.0 \\
(69.3) \\
\end{array}$ \\
\hline Nepali & $\begin{array}{c}275 \\
(208-342)^{*+\#}\end{array}$ & $\begin{array}{c}286 \\
(42.1)\end{array}$ & $\begin{array}{c}0.914 \\
(0.680-1.15)^{* *+}\end{array}$ & $0.908(0.133)$ & $\begin{array}{c}24.0 \\
(-40.3-88.3)^{+}\end{array}$ & $\begin{array}{l}24.9 \\
(36.1)\end{array}$ \\
\hline
\end{tabular}

${ }^{\dagger}$ Adjusted for age, sex

${ }^{*} \mathrm{p}<0.05$

$* * \mathrm{p}<0.01$

${ }^{+}$Group significantly varies from English, $\mathrm{p}<0.05$

*Group significantly varies from Spanish, $\mathrm{p}<0.05$ 
KANSAS JOURNAL of MEDICINE

MEDICATION ADHERENCE IN LEP PATIENTS

continued.

Table 3. Values of medication by language concordance.

\begin{tabular}{|c|c|c|c|c|c|c|}
\hline & \multicolumn{2}{|c|}{$\begin{array}{c}\text { Actual Days Medication Adherence } \\
\text { (Mean, SD) }\end{array}$} & \multicolumn{2}{|c|}{$\begin{array}{c}\text { Adherence Ratio } \\
\text { (actual days/expected days of adherence) } \\
\text { (Mean, SD) }\end{array}$} & \multicolumn{2}{|c|}{$\begin{array}{c}\text { Maximum Days Non-Adherent } \\
\text { (Mean, SD) }\end{array}$} \\
\hline & Concordant visits & Non-concordant visits & Concordant visits & Non-concordant visits & Concordant visits & Non-concordant visits \\
\hline \multicolumn{7}{|l|}{ Regular insulin } \\
\hline English $(n=4)$ & $51(43)$ & $\mathrm{n} / \mathrm{a}$ & $0.51(0.35)$ & $\mathrm{n} / \mathrm{a}$ & $127.5(164)$ & $\mathrm{n} / \mathrm{a}$ \\
\hline Spanish $(n=6)$ & $\mathrm{n} / \mathrm{a}$ & $158(125)$ & $\mathrm{n} / \mathrm{a}$ & $0.67(0.41)$ & $\mathrm{n} / \mathrm{a}$ & $37(56)$ \\
\hline Nepali $(n=2)$ & $260(84)^{*}$ & $231(99)$ & $0.78(0.31)$ & $0.68(0.27)$ & $75(106)$ & $65.5(51.3)$ \\
\hline \multicolumn{7}{|l|}{ NPH-insulin } \\
\hline English $(n=4)$ & $208(155)$ & $\mathrm{n} / \mathrm{a}$ & $0.89(0.04)$ & $\mathrm{n} / \mathrm{a}$ & $12(8)$ & $\mathrm{n} / \mathrm{a}$ \\
\hline Spanish $(\mathrm{n}=9$ & $\mathrm{n} / \mathrm{a}$ & $142(112.5)$ & $\mathrm{n} / \mathrm{a}$ & $0.60(0.33)$ & $\mathrm{n} / \mathrm{a}$ & $58(46)$ \\
\hline Nepali $(n=12)$ & $291(32)$ & $176(136)$ & $0.86(0.11)$ & $0.62(0.41)$ & $40(41)$ & $99(121)$ \\
\hline \multicolumn{7}{|l|}{ Metformin } \\
\hline English $(\mathrm{n}=3)$ & $142(130)$ & $\mathrm{n} / \mathrm{a}$ & $0.61(0.46)$ & $0.61(0.46)$ & $85(120)$ & $\mathrm{n} / \mathrm{a}$ \\
\hline Spanish $(\mathrm{n}=9$ & $90(0)$ & $194(88)$ & $0.43(0)$ & $0.87(0.16)$ & $118(0)$ & $35.7(41)$ \\
\hline Nepali $(n=20)$ & $273(74)^{* * *}$ & $174(112)$ & $0.93(0.11)$ & $0.69(0.35)$ & $19(30)$ & $42(45)$ \\
\hline \multicolumn{7}{|l|}{ ACE inhibitor } \\
\hline English $(\mathrm{n}=3)$ & $135(135)$ & $\mathrm{n} / \mathrm{a}$ & $0.65(0.64)$ & $\mathrm{n} / \mathrm{a}$ & $125(237)$ & $\mathrm{n} / \mathrm{a}$ \\
\hline Spanish $(\mathrm{n}=8)$ & $\mathrm{n} / \mathrm{a}$ & $179(112.5)$ & $\mathrm{n} / \mathrm{a}$ & $0.65(0.33)$ & $\mathrm{n} / \mathrm{a}$ & $73(69)$ \\
\hline Nepali $(\mathrm{n}=10)$ & $294(54)$ & $272(32)$ & $0.91(0.16)$ & $0.88(0.13)$ & $26(44)$ & $30(33)$ \\
\hline
\end{tabular}

" $\mathrm{p}<0.05,{ }^{* *} \mathrm{p}=0.07$

This was contrary to the authors hypothesis that patients' adherence to medications could be impacted by the patient's LEP status. The primary driver of participants' adherence was not their preferred language, but whether they had a provider who spoke the same language. It is important to reiterate that all encounters were conducted either with a language concordant provider or with the use of a professional medical interpreter. We also noted the high number of total medications patients consumed, on average. This too may have impacted medication adherence. Other unmeasured factors, such a high carbohydrate, culturally preferred diet also may have confounded our results. The study was underpowered, leading to wide confidence intervals in the language concordance analysis. Further research, recruiting more study participants, should be directed at studying provider-patient factors, such as level of education about refugees, cultural awareness, language(s) spoken by provider and patient, and availability of interpreters in the clinical encounter. Qualitative interviews also may be a useful way to assess these factors.

The finding that Nepali-speaking patients had higher average $\mathrm{HbAlc}$, took more medications, and had higher average Adherence Ratios (i.e., more compliant with regimen) compared to the Englishpreference patients, suggested that, although these patients were filling their medications consistently, the actual administration, dosing, and consistent use of these medicines may not have matched the physiciandirected regimen. Again, qualitative interviews would be useful to investigate this further.
The Adherence Ratio provided the most interpretable and actionable information and could be used clinically to assess a patient's adherence to medication regimen. As this was a quality improvement study, the goal was to use a metric that could, at least in theory, be utilized in a clinic as an objective measure to assess medication adherence, and for successful disease management. One systematic review demonstrated studies using various methods for assessing medication adherence including patient report, Medication Event Monitoring System, electronic monitoring systems, qualitative interviews, and urine assays. ${ }^{14}$ The authors concluded that there was a lack of congruence among studies in the way adherence was measured and reported. As the literature did not show a consistent, validated metric for the proposed question and the study design did not permit the adoption of patient reporting or direct patient contact as means for collecting medication adherence, it was decided to use to medication Adherence Ratio as the most efficient and useful means to answer the question. However, as stated, the usefulness of the metrics may be limited in that they do not assess how administration of medication occurs once the patient has the medicine in hand, or any other more qualitative factor in the use of the drug. On the other hand, the data provided by the metrics provided a valuable step in assessing medication adherence, since a patient cannot take prescription medication that they have not received from a pharmacy.

This study was limited by the small number of participants. Some of the medication data collected, such as that for sulfonylureas, DPP-4 
inhibitors, and thiazolidinediones, did not have adequate data points to be meaningful or draw statistical inferences from them and were excluded from the results. Additionally, one of the primary endpoints, Maximum Days Non-Compliant, showed significant heteroskedasticity by the Breusch-Pagan/Cook-Weisberg test, suggesting that this outcome may not be valid for comparing language groups. Another limitation of the study was that it was possible the patients were filling medications at pharmacies other than what was listed in the EMR. Some patients had more than one pharmacy documented in the EMR, but it is conceivable that they were using other, unlisted pharmacies without the awareness of the clinical team. Finally, an important limitation of the study was that the authors assumed that the Latin(x) English-speaking patients also spoke Spanish. This was not data collected from the EMR but it was inferred from the patients' stated ethnicity.

\section{CONCLUSIONS}

Patients with LEP often have worse clinical outcomes than their American-born and English-speaking counterparts. ${ }^{69}$ A way to improve these outcomes is to ensure proper adherence to medication regimen. This study found that on average, Nepali-speaking patients with LEP had higher rates of adherence as measured by the Adherence Ratio for diabetic medications than English-preference or Spanish-speaking patients who identified as Latin(x). Yet, these same Nepali-speaking patients, who were largely Bhutanese refugees, had higher HbAlc measurements than the Spanish-speaking patients while being similar to the English-preference cohort in respects to HbAlc. Additionally, the observed differences in the language groups resolved upon stratification by patient-provider language concordance. More research is needed to evaluate other underlying causes of medication non-adherence in these populations and improve management of chronic conditions.

\section{REFERENCES}

${ }^{1}$ U.S. Census Bureau. Detailed Languages Spoken at Home and Ability to Speak English for the Population 5 Years and Over: 2009-2013. 2015. https://www.census.gov/data/tables/2013/demo/2009-2013-lang-tables. html.

2 Alzubaidi H, McNarmara K, Kilmartin GM, Kilmartin JF, Marriott J. The relationships between illness and treatment perceptions with adherence to diabetes self-care: A comparison between Arabic-speaking migrants and Caucasian English-speaking patients. Diabetes Res Clin Pract 2015; 110(2):208-217. PMID: 26415673.

${ }^{3}$ Njeru JW, Boehm DH, Jacobson DJ, et al. Diabetes outcome and process measures among patients who require language interpreter services in Minnesota primary care practices. J Community Health 2017; 42(4):819-825. PMID: 28229264.

${ }^{4}$ Capps R, Newland K, Fratzke S, et al. The Integration Outcomes of U.S. Refugees: Successes and Challenges. 2015. https://www.migrationpolicy. org/sites/default/files/publications/UsRefugeeOutcomes-FINALWEB. pdf.

${ }^{5}$ Shahin W, Stupans I, Kennedy G. Health beliefs and chronic illnesses of refugees: A systematic review. Ethn Health 2018; 26(5):756-768. PMID: 30537853.

${ }^{6}$ Sharif MZ, Biegler K, Mollica R, et al. A health profile and overview of healthcare experiences of Cambodian American refugees and immigrants residing in southern California. J Immigr Minor Health 2019; 21(2):346355. PMID: 29705910.

7 Kumar GS, Beeler JA, Seagle EE, Jentes ES. Long-term physical health outcomes of resettled refugee populations in the United States: A scoping review. J Immigr Minor Health 2021; 23(4):813-823. PMID: 33515162.

${ }^{8}$ Fernandez A, Schillinger D, Warton EM, et al. Language barriers, physician-patient language concordance, and glycemic control among insured Latinos with diabetes: The Diabetes Study of Northern California (DISTANCE). J Gen Intern Med 2011; 26(2):170-176. PMID: 20878497.
KANSAS JOURNAL of MEDICINE

MEDICATIONADHERENCE IN LEP PATIENTS

continued.

${ }^{9}$ Karliner LS, Jacobs EA, Chen AH, Mutha S. Do professional interpreters improve clinical care for patients with limited English proficiency? A systematic review of the literature. Health Serv Res 2007; 42(2):727-754. PMID: 17362215.

${ }^{10}$ Bellamy K, Ostini R, Martini N, Kairuz T. Access to medication and pharmacy services for resettled refugees: A systematic review. Aust J Prim Health 2015; 21(3):273-278. PMID: 25577397.

${ }^{11}$ Hall E, Lee SY, Clark PC, Perilla J. Social ecology of adherence to hypertension treatment in Latino migrant and seasonal farmworkers. J Transcult Nurs 2016; 27(1):33-41. PMID: 24855134.

${ }^{12}$ Lee A, Buchwald D, Hooton TM. Knowledge and compliance with medications in South East Asian refugees. J Clin Pharm Ther 1993; 18(3):199-204. PMID: 8345005.

13 Peeters B, Van Tongelen I, Duran Z, et al. Understanding medication adherence among patients of Turkish descent with type 2 diabetes: A qualitative study. Ethn Health 2015; 20(1):87-105. PMID: 24588791.

${ }_{14}$ Hu D, Juarez DT, Yeboah M, Castillo TP. Interventions to increase medication adherence in African-American and Latino populations: A literature review. Hawaii J Med Public Health 2014; 73(1):11-18. PMID: 24470982.

Keywords: patient compliance, diabetes mellitus, communication barriers, physician-patient relations, medication adherence 